\title{
Formation and stabilization of environmentally persistent free radicals induced by the interaction of anthracene with Fe(III)-modified clays
}

\author{
Hanzhong Jia ${ }^{\mathrm{a}}$, Gulimire Nulaji ${ }^{\mathrm{a}}$,, Hongwei Gao ${ }^{\mathrm{a}}, \mathrm{Fu}_{\mathrm{Wang}}{ }^{\mathrm{a}}$, Yunqing Zhu ${ }^{\mathrm{a}}$, and Chuanyi \\ Wang $^{\mathrm{a}} *$ \\ ${ }^{a}$ Laboratory of Environmental Sciences and Technology, Xinjiang Technical Institute of \\ Physics \& Chemistry; Key Laboratory of Functional Materials and Devices for Special \\ Environments, Chinese Academy of Sciences, Urumqi 830011, China. \\ ${ }^{\mathrm{b}}$ School of Geology and Mining Engineering, Xinjiang University, Urumqi 830046, China.
}

Pages: 10

Figures: 8

Tables: 1 


\section{Supporting Information}

\section{CHEMICALS AND MATERIALS:}

\section{Chemicals.}

Anhydrous ferric chloride $\left(\mathrm{FeCl}_{3}\right)$, sodium chloride $(\mathrm{NaCl})$, sodium hydroxide $(\mathrm{NaOH})$, hydrochloride acid ( $\mathrm{HCl}, 36 \sim 38 \%$ ), hydrofluoric acid (HF, 48\%), perchloric acid $\left(\mathrm{HClO}_{4}, 70 \%\right)$, nitric acid $\left(\mathrm{HNO}_{3}, 68-70 \%\right)$ were obtained from Sinopharm

Chemical Reagent Co., Ltd (Shanghai, China). Phenanthrene (Phe, 98\%), anthracene (Ant, 98\%), pyrene (Pyr, 99\%), benzo[a]pyrene (B[a]P, 98.5\%) and methanol (HPLC-grade solvent) were purchased from Sigma-Aldrich (Shanghai, China). All the chemicals were used as received.

Table S1. Iron contents and relevant characteristics of original and Fe(III)-saturated montmorillonite, illite, and kaolinite clays.

\begin{tabular}{cccccc}
\hline Clays & $\mathrm{CEC}^{\mathrm{a}}$ & Specific & \multicolumn{3}{c}{ Fe content of clay minerals (\%) } \\
\cline { 4 - 6 } & $\begin{array}{c}\left(\mathrm{cmol}^{-1}\right) \\
\left.\mathrm{kg}^{-1}\right)\end{array}$ & $\begin{array}{c}\text { surface area } \\
\mathrm{b}\left(\mathrm{m}^{2} \mathrm{~g}^{-1}\right)\end{array}$ & $\begin{array}{c}\text { Original } \\
\text { clays }\end{array}$ & $\begin{array}{c}\text { Fe(III)-saturated } \\
\text { clays }\end{array}$ & $\begin{array}{c}\text { Surface } \\
\text { Fe(III) }\end{array}$ \\
\hline Montmorillonite & 82 & 82.1 & 2.80 & 5.92 & 3.12 \\
Illite & 26 & 89.5 & 2.76 & 4.30 & 1.54 \\
Kaolinite & 9.5 & 8.7 & 0.07 & 0.51 & 0.44 \\
\hline
\end{tabular}

${ }^{a} \mathrm{CEC}$ was obtained by adding $30 \mathrm{~mL}$ of $0.2 \mathrm{M} \mathrm{NH}_{4} \mathrm{Cl}$ to a $50-\mathrm{mL}$ polypropylene centrifuge tube containing $4 \mathrm{~g}$ of air-dried clay minerals. The tubes were shaken for 1 $\mathrm{h}$ on a side-to-side shaker and then were centrifuged for $10 \mathrm{~min}$ at $9000 \mathrm{rpm}$. Clear supernatant was collected, and then the clay was rewashed with $\mathrm{NH}_{4} \mathrm{Cl}$ solution for a total of three times. The exchangeable cations, such as $\mathrm{K}^{+}, \mathrm{Na}^{+}, \mathrm{Ca}^{2+}, \mathrm{Mg}^{2+}, \mathrm{Al}^{3+}$, in supernatant from the three consecutive washes were analyzed by inductively coupled plasma mass spectrometry (Agilent 7500a). The CEC value was calculated by the sum of those exchangeable cations. ${ }^{b}$ Specific surface area was measured by nitrogen gas adsorption isotherms at $77 \mathrm{~K}$ within $\mathrm{P} / \mathrm{P}_{0}$ valuesof $10^{-5}$ to 0.999 using a volumetric vacuum apparatus (Quantachrome Autosorp1C). 

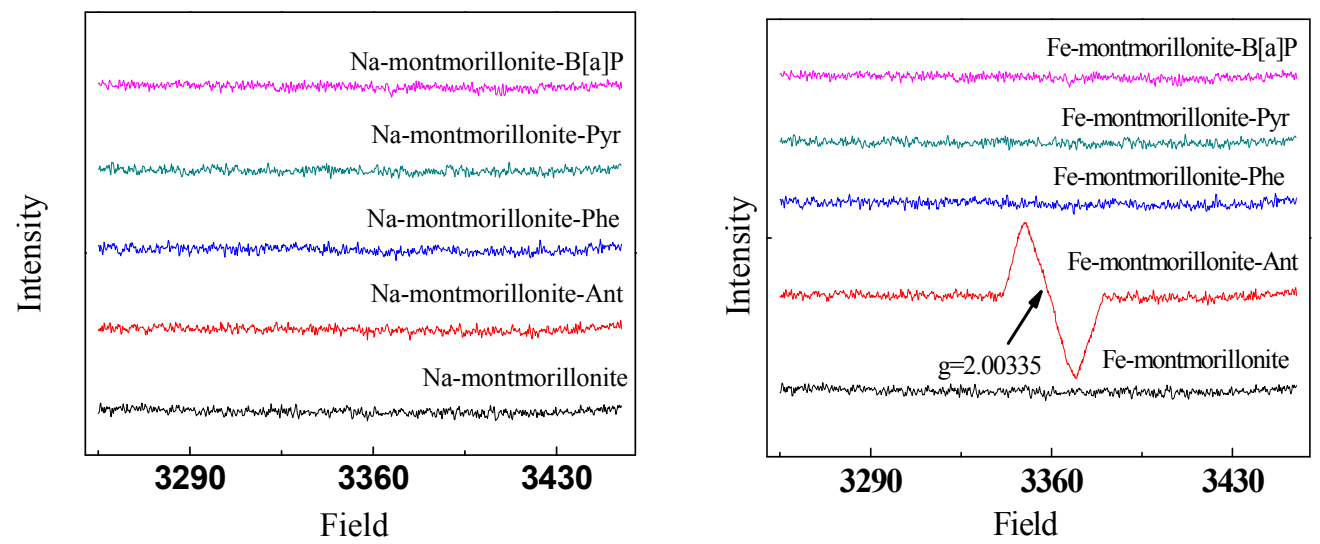

Fig. S1. EPR spectra of various PAHs-contaminated $\mathrm{Na}(\mathrm{I})$-montmorillonite and $\mathrm{Fe}(\mathrm{III})$-montmorillonite after $10 \mathrm{~d}$ of reaction. 

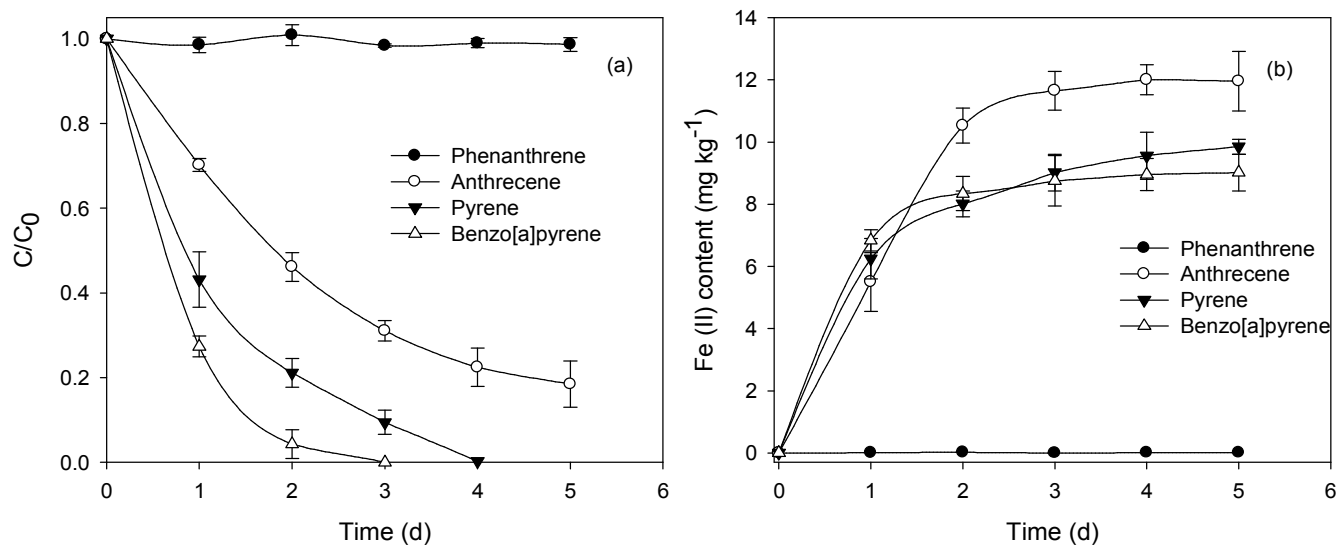

Fig. S2. (a) Kinetics of PAHs transformation on Fe(III)-montmorillonite. (b) Kinetics of $\mathrm{Fe}(\mathrm{II})$ formation in the of PAHs-Fe(III)-montmorillonite system. 

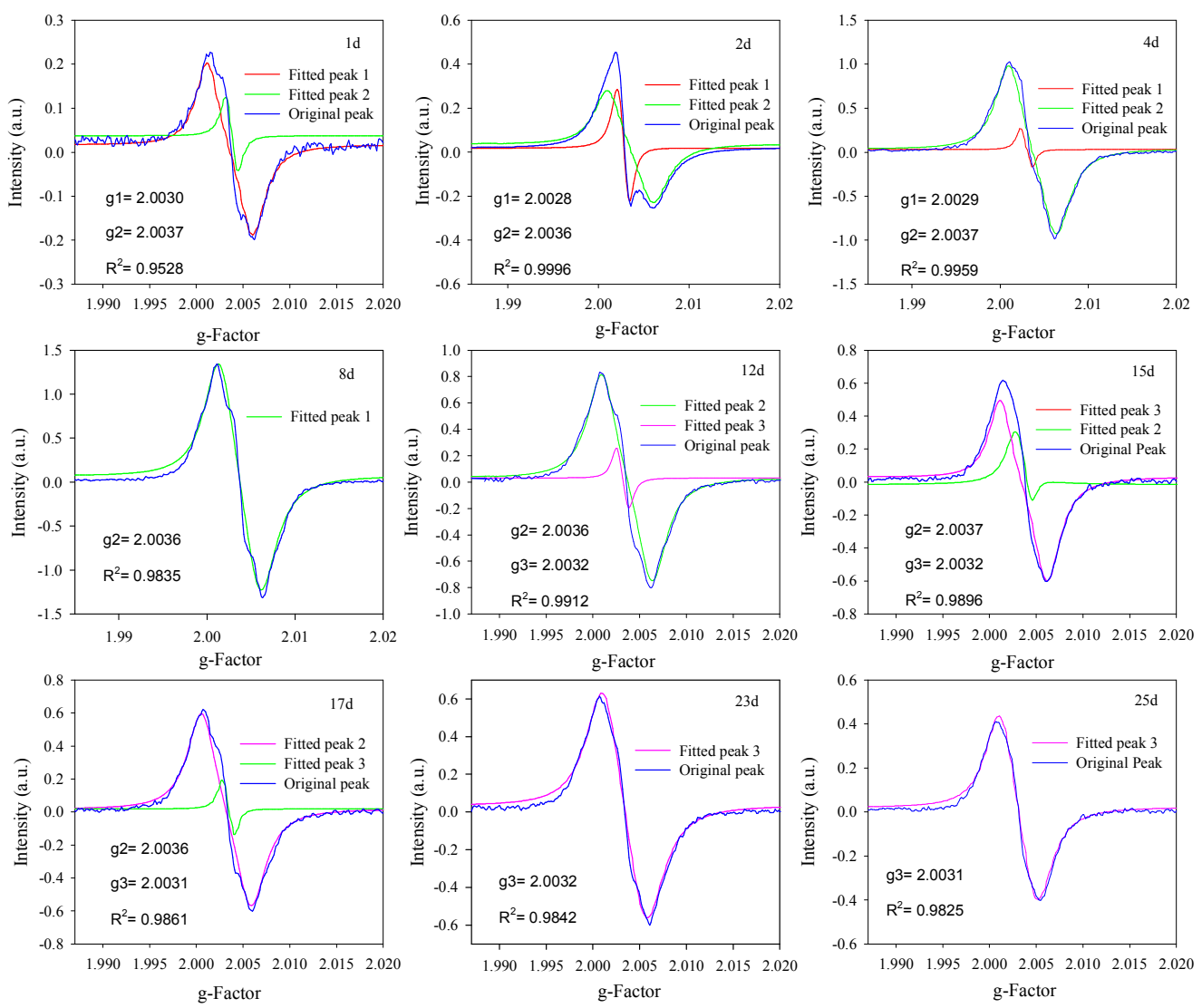

Fig. S3. Spectral de-convolution of EPR signals for the reaction system of anthracene-contaminated $\mathrm{Fe}(\mathrm{III})$-montmorillonite in air with $\mathrm{RH}$ of $\sim 8 \%$. 

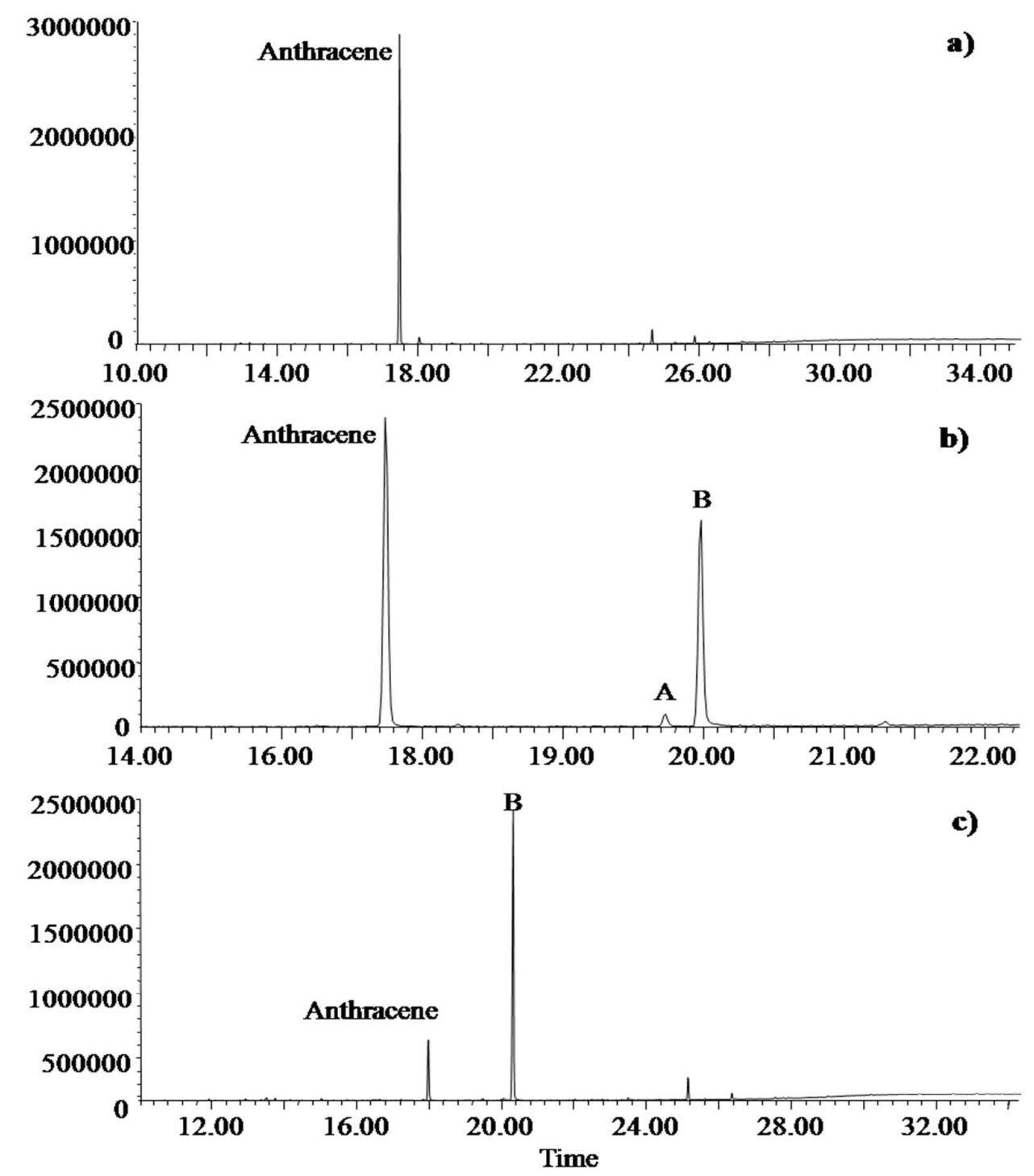

Fig. S4. GC-MS chromatograms of extracted Fe(III)-montmorillonite/anthracene of reaction mixture after (a) $0 \mathrm{~d}$, (b) $5 \mathrm{~d}$, and (c) $10 \mathrm{~d}$ reaction. 


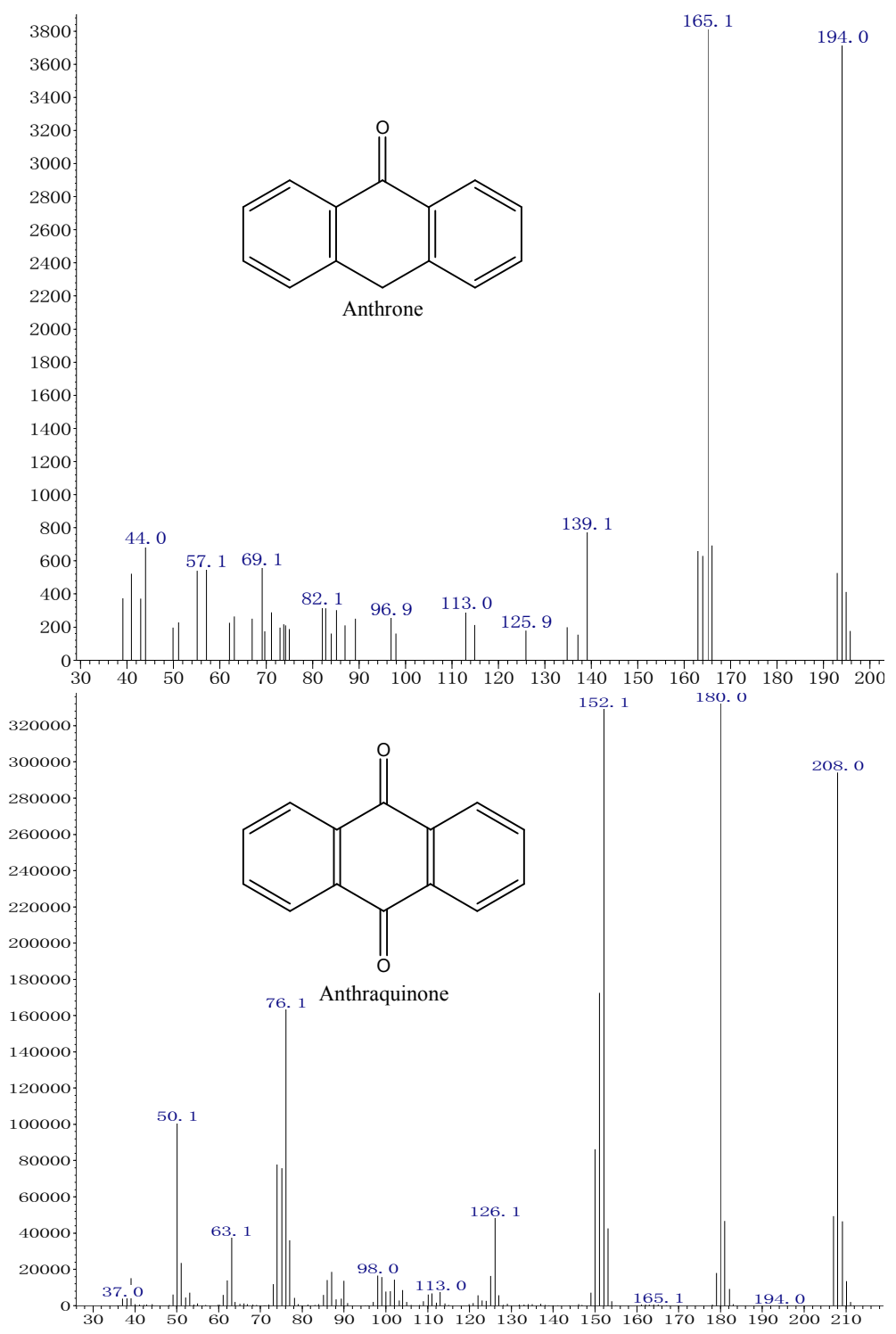

Fig. S5. Mass spectra of relevant products: product A (anthrone) and product B (anthraquinone). 


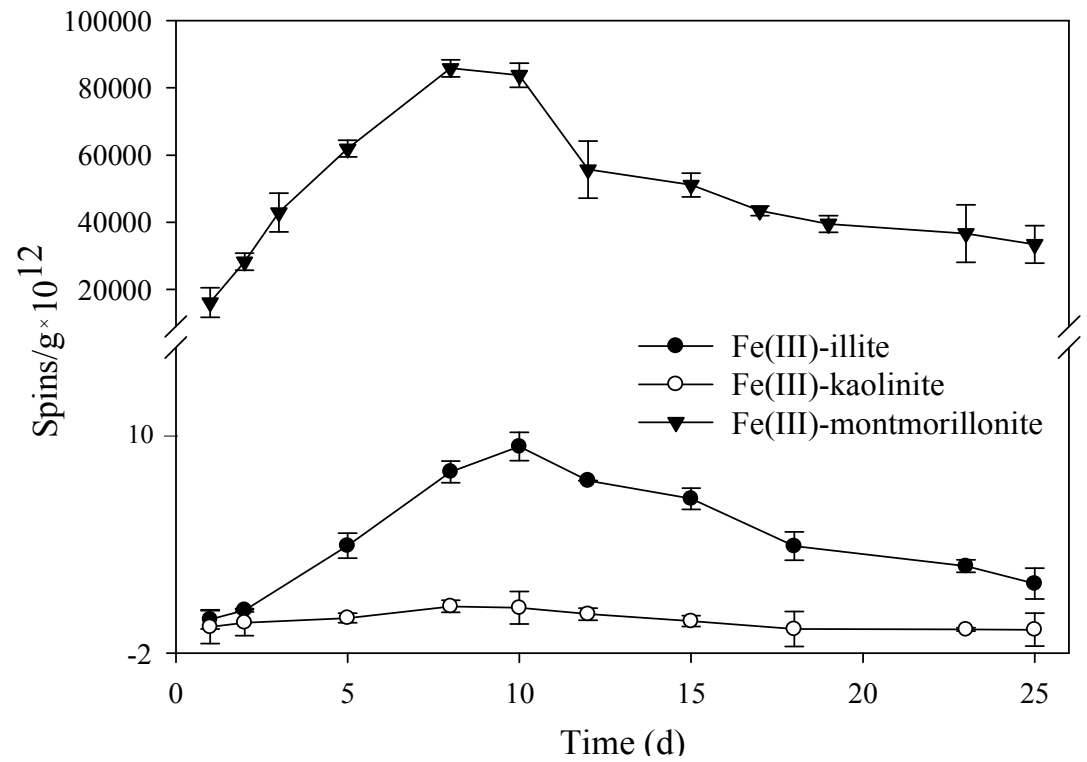

Fig. S6. The evolution of radical concentration as a function of reaction time for anthracene-contaminated Fe(III)-illite, Fe(III)-kaolinite, and Fe(III)-montmorillonite. 

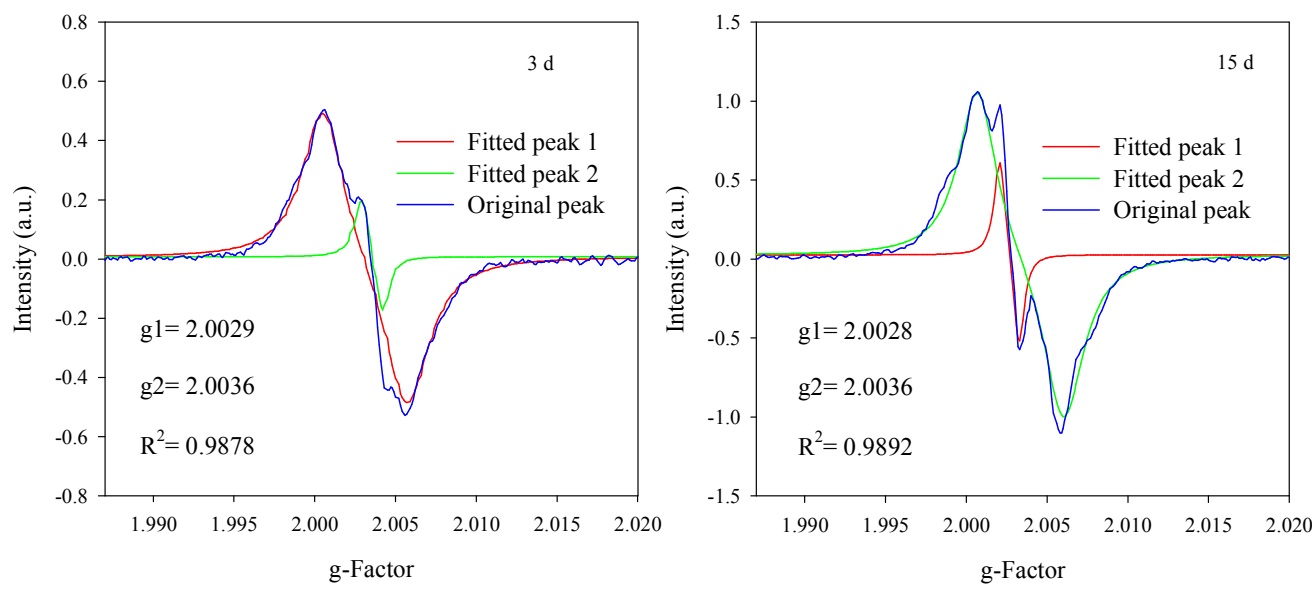

Fig. S7. Spectral de-convolution of EPR signals for the reaction system of anthracene-contaminated $\mathrm{Fe}(\mathrm{III})$-montmorillonite in anoxic condition without free $\mathrm{O}_{2}$ and $\mathrm{H}_{2} \mathrm{O}$ molecules. 


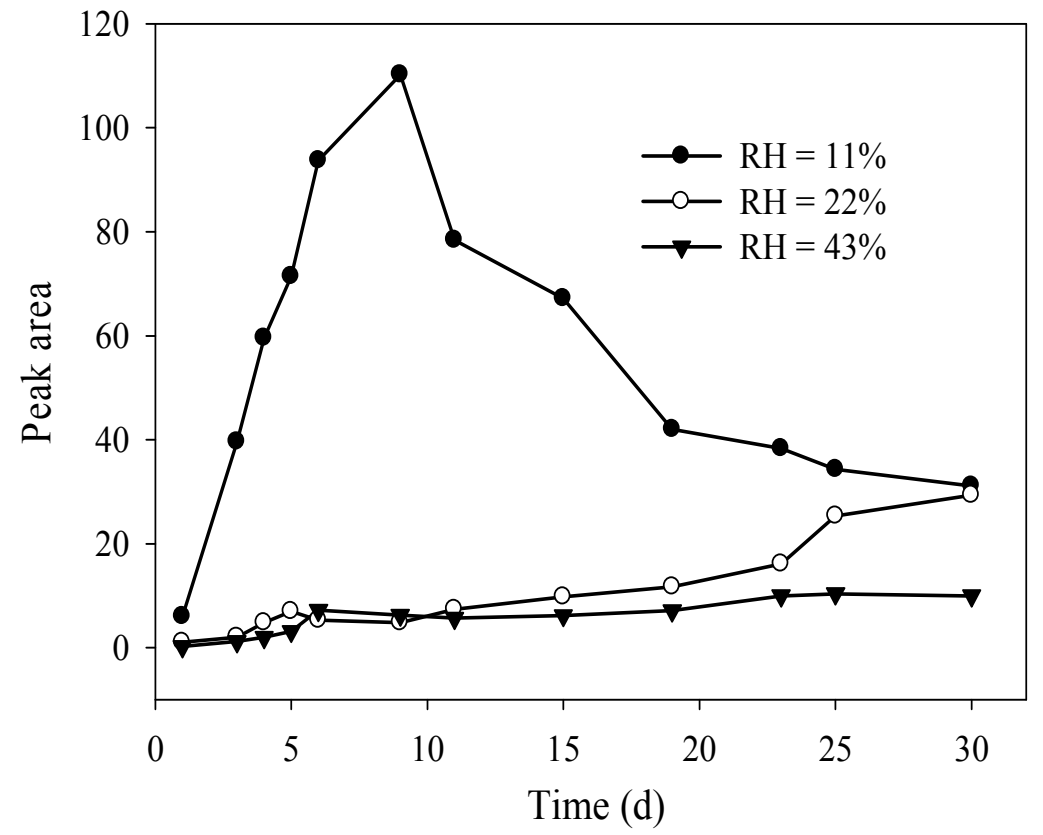

Fig. S8. The evolution of EPR spectra peak area as a function of reaction time in the anthracene-contaminated $\mathrm{Fe}(\mathrm{III})$-montmorillonite systems at different relative humidity. 